\title{
Evolving progress in oncologic and operative outcomes for esophageal and junctional cancer: Lessons from the experience of a high-volume center
}

\author{
John V. Reynolds, MD, ${ }^{\text {a }}$ Claire L. Donohoe, MB, ${ }^{\mathrm{a}}$ Erin McGillycuddy, MSc, ${ }^{\text {a }}$ Naraymasamy Ravi, MD, ${ }^{\mathrm{a}}$ \\ Dermot O'Toole, MD, ${ }^{b}$ Ken O'Byrne, $\mathrm{MD},{ }^{\mathrm{c}}$ and Donal Hollywood, $\mathrm{MD}^{\mathrm{c}}$
}

\begin{abstract}
Objective: Modern series from high-volume esophageal centers report an approximate $40 \% 5$-year survival in patients treated with curative intent and postoperative mortality rates of less than $4 \%$. An objective analysis of factors that underpin current benchmarks within high-volume centers has not been performed.
\end{abstract}

\begin{abstract}
Methods: Three time periods were studied, 1990 to 1998 (period 1), 1999 to 2003 (period 2), and 2004 to 2008 (period 3), in which 471, 254, and 342 patients, respectively, with esophageal cancer were treated with curative intent. All data were prospectively recorded, and staging, pathology, treatment, operative, and oncologic outcomes were compared.
\end{abstract}

\begin{abstract}
Results: Five-year disease-specific survival was $28 \%, 35 \%$, and $44 \%$, and in-hospital postoperative mortality was $6.7 \%, 4.4 \%$, and $1.7 \%$ for periods 1 to 3 , respectively $(P<.001)$. Period 3 , compared with periods 1 and 2 , respectively, was associated with significantly $(P<.001)$ more early tumors $(17 \%$ vs $4 \%$ and $6 \%)$, higher nodal yields (median 22 vs 11 and 18), and a higher R0 rate in surgically treated patients ( $81 \%$ vs $73 \%$ and $75 \%$ ). The use of multimodal therapy increased $(P<.05)$ across time periods. By multivariate analysis, age, $\mathrm{T}$ stage, $\mathrm{N}$ stage, vascular invasion, $\mathrm{R}$ status, and time period were significantly $(P<.0001)$ associated with outcome.
\end{abstract}

Conclusions: Improved survival with localized esophageal cancer in the modern era may reflect an increase of early tumors and optimized staging. Important surgical and pathologic standards, including a higher R0 resection rate and nodal yields, and lower postoperative mortality, were also observed. (J Thorac Cardiovasc Surg 2012;143:1130-7)

Supplemental material is available online.

\section{Earn CME credits at}

http://cme.ctsnetjournals.org

The curative approach to esophageal and junctional cancer is historically associated with poor outcomes, with cure rates of approximately $20 \%$ and a risk of operative morbidity and mortality greater than for any other cancer operation. ${ }^{1}$ Of note, several reports from high-volume centers suggest significant recent advances in outcomes, with cure rates of approximately $40 \%$ and an in-hospital

From the Departments of Surgery, ${ }^{\mathrm{a}}$ Medicine, ${ }^{\mathrm{b}}$ and Clinical and Medical Oncology, St James's Hospital and Trinity College, Dublin, Ireland.

Disclosures: Authors have nothing to disclose with regard to commercial support.

Received for publication Aug 4, 2011; revisions received Nov 3, 2011; accepted for publication Dec 6, 2011; available ahead of print Jan 13, 2012.

Address for reprints: John V. Reynolds, MD, Professor of Surgery, Trinity Centre for Health Sciences, St. James’ Hospital, Dublin 8, Ireland (E-mail: reynoljv@tcd.ie). $0022-5223 / \$ 36.00$

Copyright (C) 2012 by The American Association for Thoracic Surgery doi:10.1016/j.jtcvs.2011.12.003 postoperative mortality of less than $4 \% .^{2-4}$ General factors that may underpin this improvement include more accurate staging enabling precise treatment planning, improved physiologic risk assessment for surgery, advances in perioperative care, earlier diagnosis through greater awareness of Barrett's esophagus and strict surveillance, lower thresholds for endoscopy, and the use of neoadjuvant and adjuvant therapies. ${ }^{5-7}$ The key organizational element underpinning improved outcomes may be the increasing trend for oncologic resections to the domain of specialist high-volume surgeons working in multidisciplinary teams in high-volume hospitals. ${ }^{5,8}$

The evidence in support of restricting esophageal cancer surgery to high-volume centers is unassailable, but within high-volume centers the structure and process factors associated with improved oncologic and operative outcomes are rarely studied. In addition to volume, measures of structure include specialization, organization, and centralization. Process measures include staging, multidisciplinary decisionmaking and planning, neoadjuvant and adjuvant therapies, type of surgery, perioperative care, and pathologic reporting. The Esophageal and Gastric Cancer Center at St James's Hospital in Dublin is a high-volume esophageal center. The pattern of disease in Ireland, with adenocarcinoma the most common cancer, is representative of what is observed in North America and much of Europe. ${ }^{6}$ There is no national 


\author{
Abbreviations and Acronyms \\ $\mathrm{AEG}=$ adenocarcinoma of the esophagogastric \\ junction \\ $\mathrm{CT}=$ computed tomography \\ EUS $=$ endoscopic ultrasound \\ PET $=$ positron emission tomography \\ $\mathrm{TRG}=$ tumor regression grade
}

centralization or a national Barrett's surveillance program. With no major structural changes, a significant quality improvement in operative and oncologic outcomes was nonetheless observed over time, and the aim of this study was to analyze patterns of care and key factors that may be associated with the outcomes evident in the current era.

\section{MATERIALS AND METHODS}

Patients attending the Center between 1990 and 2008 with a diagnosis of cancer of the esophagus or esophagogastric junction were included. The study focused on patients treated with curative intent, defined as pretreatment staging of $\mathrm{T}_{0-3}, \mathrm{~N}$ any, and $\mathrm{M}_{0}$, and considered fit enough to undergo treatment. Selected patients with cT4 disease were also treated with curative intent. Adenocarcinoma of the esophagogastric junction (AEG) included tumors that had their center within $5 \mathrm{~cm}$ proximal or distal of the anatomic cardia, identified endoscopically, and were classified per the Siewert criteria. ${ }^{9}$ All data are prospectively recorded in a database (Dendrite, London, UK). The study was approved by the institutional review board.

\section{Structures}

The St James's Hospital is a high-volume center for esophageal and junctional cancer operating since the mid-1970s. Surgeons are defined as upper gastrointestinal surgeons, not thoracic surgeons, and undertake at minimum 30 major esophageal resections each per annum. The esophageal program has been aligned with dedicated intensive care specialists and thoracic anesthetists throughout the study period.

\section{Process}

Computed tomography (CT) of the neck, thorax, and abdomen became standard in 1995 but was used only sporadically between 1990 and 1995 . The use of ${ }^{18}$-F-deoxyglucose positron emission tomography (PET) scans was introduced in 2003 and has been performed as a combined CT-PET since early 2006. Endoscopic ultrasound (EUS) was available on an inconsistent basis since 1993 and has been routine since 2007 with the appointment of a dedicated EUS specialist. Laparoscopy is standard for locally advanced tumors below the diaphragm.

A formal multidisciplinary team was established in 1999, including an advanced nurse specialist and defined lead clinicians in surgery, medical and radiation oncology, radiology, pathology, and gastroenterology. A weekly conference to discuss all new cases has been in place since 1999, and conference proceedings have been audited since 2004. A weekly esophageal clinic with attendance by surgeons, nurse specialists, and nutritionists, and same-day linkage to gastroenterology, medical, and radiation oncologists has been operational since 2004.

Preoperative chemoradiation is the preferred multimodal approach for patients with predicted locally advanced tumors. A randomized trial of multimodal therapy versus surgery alone was performed at this center between 1990 and $1995 .{ }^{6}$ There have been no changes to the chemoradiation regimen or dosing schedule over the study period since the time of this trial and no other trial performed. Patients with AEG type III tumors have been considered for postoperative chemoradiation and more recently for preand postoperative chemotherapy. ${ }^{10,11}$

For surgery, the principle of wide clearance and a radical lymphadenectomy is the goal in all cases, with the extent of resection influenced by the location of the tumor, comorbidities, cardiac and respiratory function, and local extent of the tumor. ${ }^{12,13}$ The usual standard for esophageal tumors is an abdominal-thoracic en bloc esophagectomy. A transhiatal esophagectomy is considered for patients with clinical T1 and predicted node-negative disease or for higher-risk operative cases due to age or respiratory comorbidity. For patients with AEG type III tumors, an extended total gastrectomy and an anastomosis via a transmediastinal approach or separate thoracotomy is performed. Endoscopic mucosal resection was introduced in 2007 and is applied to patients with high-grade dysplasia or tumors that by EUS assessment do not invade the submucosa (uT1a).

Patient assessment for fitness for surgery or multimodal therapy has been largely unchanged since 1990, with the absence of major respiratory disease being the key clinical criteria, as well as satisfactory pulmonary function test results (forced expiratory volume in 1 second $>1.5 \mathrm{~L}$ ) and performance status as previously described. ${ }^{13}$ Thoracic epidurals have been used since 1992. All patients are extubated immediately postoperatively and managed in a high-dependency unit or intensive care unit before transfer to a specialist surgical ward. All patients receive early enteral nutrition via a needle catheter jejunostomy. Perioperative care protocols have been relatively uniform since 1996 but were not standardized or audited during this study period. All complications, major and minor, were defined and prospectively audited, as previously described. ${ }^{13}$

Pathologic assessment is performed per standard guidelines. ${ }^{14}$ All margins (proximal, distal, and circumferential) were assessed, as well as tumor differentiation, lymphovascular invasion, and perineural invasion. An R1 deep (circumferential) margin denotes tumor within $1 \mathrm{~mm}$ of the resection margin. The database was adapted and retrospectively classified in 2010 to include the new 7th edition AJCC Cancer Staging Manual N staging classification for esophageal and junctional tumors. ${ }^{15}$ In patients treated with neoadjuvant therapy, the extent of residual carcinoma in the esophagectomy specimen was assigned per Mandard and colleagues ${ }^{16}$ : Tumor regression grade (TRG) 1 represents a complete response; TRG2 represents rare residual cancer cells scattered throughout the fibrosis; TRG3 represents an increase in the number of residual cancer cells, but fibrosis still predominates; TRG4 represents residual cancer cells outgrowing fibrosis; and TRG5 represents a complete absence of regression.

Patients are followed at the Esophageal Clinic at 3 monthly intervals for the first year and at 4 to 6 monthly intervals for the subsequent 4 years. All patients had CT scans in the first and second post-treatment years or as clinically indicated.

\section{Statistics}

Three time periods were compared: period 1, from 1990, when prospective records commenced, and a randomized clinical trial (1990-1995), to 1998 inclusive; period 2, from 1999, when a defined multidisciplinary team was established, with nurse specialization, to 2003; and period 3, from 2004 to 2008 inclusive, where multidisciplinary team structure was well established and processes audited. Statistical analysis was performed using the Statistical Package for the Social Sciences version 16.0 (SPSS Inc, Chicago, Ill). Continuous variables were compared using unpaired $t$ tests, and categoric variables were assessed using the chi-square test. Survival statistics were calculated using the Kaplan-Meier method, and the log-rank test was used to assess differences in disease-specific survival between groups. Survival time was measured from the date of diagnosis to the date of an event or last follow-up. Independent variables were entered into a multivariate Cox proportional hazards model with a forward likelihood ratio selection procedure. A significance level of .05 was used for all analyses, and all $P$ values reported are 2-tailed. 
TABLE 1. Tumor site and morphology in patients treated with curative intent

\begin{tabular}{|c|c|c|c|c|c|c|c|}
\hline \multirow{2}{*}{$\frac{\text { Time period }}{\text { Morphology }}$} & \multicolumn{2}{|c|}{ 1990-1998 } & \multicolumn{2}{|c|}{ 1999-2003 } & \multicolumn{2}{|c|}{ 2004-2008 } & \multirow[t]{2}{*}{$P$ value } \\
\hline & $\mathrm{n}$ & $\%$ & $\mathrm{n}$ & $\%$ & $\mathrm{n}$ & $\%$ & \\
\hline Adenocarcinoma & 271 & 57.5 & 154 & 60.6 & 222 & 64.9 & .17 \\
\hline Squamous cell & 187 & 39.7 & 93 & 36.6 & 109 & 31.8 & \\
\hline Small cell & 2 & 0.004 & 2 & 0.8 & 4 & 1.1 & \\
\hline Lymphoma & 0 & 0 & 1 & 0.4 & 1 & 0.3 & \\
\hline Other & 7 & 0.015 & 4 & 1.5 & 6 & 1.9 & \\
\hline Missing & 4 & 0.008 & 0 & 0 & 0 & 0 & \\
\hline Tumor site & $\mathrm{n}$ & $\%$ & $\mathrm{n}$ & $\%$ & $\mathrm{n}$ & $\%$ & \\
\hline AEG & 271 & 56.7 & 154 & 62.3 & 222 & 65.8 & .492 \\
\hline SCC lower third & 110 & 23.4 & 45 & 18.2 & 33 & 10.0 & \\
\hline SCC middle third & 54 & 11.5 & 38 & 15.4 & 62 & 18.7 & \\
\hline SCC upper third & 23 & 4.9 & 10 & 4.1 & 14 & 4.2 & \\
\hline AEG junction & $\mathrm{n}=271$ & $\%$ & $\mathrm{n}=154$ & $\%$ & $\mathrm{n}=222$ & $\%$ & \\
\hline AEG type 1 & 88 & 39.6 & 57 & 37.0 & 118 & 53.2 & $<.001$ \\
\hline AEG type 2 & 91 & 33.6 & 54 & 35.1 & 51 & 22.9 & \\
\hline AEG type 3 & 74 & 27.3 & 42 & 27.3 & 53 & 23.9 & \\
\hline Unspecified & 18 & 6.6 & 1 & 0.06 & 0 & 0 & \\
\hline Barrett's surveillance & 8 & 3.0 & 5 & 3.3 & 24 & 10.8 & .035 \\
\hline
\end{tabular}

$A E G$, Adenocarcinoma of the esophagogastric junction.

\section{RESULTS}

\section{Volumes, Pathology, and Treatment Intent}

Between 1990 and 2008, 1787 patients were referred with esophageal or junctional cancer, 704 in period 1, 494 in period 2, and 589 in period 3 (Table E1). The sex distribution and mean age were similar across the time periods. There was a significant $(P=.003)$ increase in the incidence of adenocarcinoma, from $55.5 \%$ and $53.2 \%$ in periods 1 and 2 , respectively, to $62 \%$, in period 3 . There was a significant $(P<.001)$ decrease in the percentage of patients treated with curative intent, from $68 \%$ in period 1 to $53 \%$ and $58 \%$ in periods 2 and 3 , respectively.

For patients treated with curative intent $(n=1067)$, the tumor site and morphology are shown in Table 1. Adenocarcinoma was the dominant pathology in each time period, with a nonsignificant increase $(P=.17)$ from $57.5 \%$ to $60.6 \%$ to $64.9 \%$ over each time period, respectively. Within the AEG cohort, AEG type 1 represented $53 \%$ in the most current time period compared with $39.6 \%$ in period 1 and $37.0 \%$ in period $2(P<.001)$. In period 3, 24 patients, representing $10.8 \%$ overall and $20.3 \%$ of patients with AEG 1, were on Barrett's surveillance compared with $3 \%$ overall in the 2 previous time periods.

\section{Staging}

Staging modalities in the different periods are shown in Table E2. In patients treated with curative intent, just $31 \%$ of patients underwent CT imaging in period 1, compared with $100 \%$ in periods 2 and 3. For PET imaging, this was performed in $82 \%$ of patients in period 3 and $11 \%$ in period 2. EUS increased from $10 \%$ and $9 \%$ in periods 1 and 2 , respectively, to $32 \%$ in period 3 , and $85 \%$ since 2007 . Since $2004,100 \%$ of patients treated with curative intent were discussed at the weekly multidisciplinary meeting.

\section{Treatment of Patients With Curative Intent}

In patients treated with curative intent, there was a significant $(P<.001)$ decrease in the use of surgery, from $94.6 \%$ in period 1 to $80.7 \%$ in period 2 and $71.1 \%$ in period 3 (Table 2). A corresponding increased use of radical chemoradiotherapy was observed, from $2.5 \%$ to $16.1 \%$ and $23.4 \%$ in periods 1 to 3 , respectively. The use of endoscopic mucosal resection for high-grade dysplasia and uT1a tumors is exclusive to the recent period, representing 5.3\% of operative approaches.

The use of multimodal therapy as a percentage of all surgical approaches increased from $28 \%$ in period 1 to $37 \%$ in period 2 and $41 \%$ in period $3(P<.001)$. In patients undergoing multimodal therapy, a similar percentage did not progress to surgery in each time period because of progressive disease or worsening performance status $(9.4 \%$ period $1,9.6 \%$ period 2 , and $16 \%$ period 3 ). In period 3 , the use of transhiatal esophagectomy increased, representing $5.8 \%$ of resections, compared with $1.8 \%$ in period 1 and $2.4 \%$ in period $2(P=.027)$.

\section{Pathologic Stage and Response to Neoadjuvant Therapy}

Surgery-only cohort. The incidence of early esophageal cancer, defined as cancer confined to the mucosal or submucosa, and including high-grade dysplasia, $\mathrm{pT} 1 \mathrm{a}$, and $\mathrm{pT} 1 \mathrm{~b}$, was $6.6 \%, 10.0 \%$, and $34.3 \%(P<.001)$ in periods 1 to 3 , respectively. pT3 tumors represented $77 \%, 57 \%$, and $45 \%$ of resections in periods 1 to 3 , respectively (Table 3 ). 
TABLE 2. Treatment details

\begin{tabular}{|c|c|c|c|c|c|c|c|}
\hline \multirow{2}{*}{$\begin{array}{l}\text { Time period } \\
\text { Treatment details of patients treated with } \\
\text { curative intent }\end{array}$} & \multicolumn{2}{|c|}{ 1990-1998 } & \multicolumn{2}{|c|}{ 1999-2003 } & \multicolumn{2}{|c|}{ 2004-2008 } & \multirow[t]{2}{*}{$P$ value } \\
\hline & $\mathrm{n}=471$ & $\%$ & $\mathrm{n}=254$ & $\%$ & $\mathrm{n}=342$ & $\%$ & \\
\hline Radical chemoradiotherapy & 12 & 2.5 & 41 & 16.1 & 80 & 23.4 & $<.001$ \\
\hline Surgery: & 446 & 94.6 & 205 & 80.7 & 243 & 71.1 & $<.001$ \\
\hline Surgery first & 320 & 71.7 & 130 & 63.4 & 131 & 54 & $<.001$ \\
\hline Multimodal completed & 126 & 28.3 & 75 & 36.6 & 99 & 40.7 & .05 \\
\hline Endoscopic mucosal resection & 0 & & 0 & & 13 & 5.3 & .0001 \\
\hline $\begin{array}{l}\text { Failed to progress to surgery after multimodal } \\
\text { therapy (of total multimodal therapy) }\end{array}$ & 13 & 9.4 & 8 & 9.6 & 19 & 16 & NS \\
\hline \multicolumn{8}{|l|}{ Type of surgery } \\
\hline 2 Phase esophagectomy & 269 & 60.3 & 110 & 53.6 & 132 & 54.3 & NS \\
\hline 3 Phase esophagectomy & 91 & 20.4 & 42 & 20.5 & 51 & 21.0 & \\
\hline Transhiatal* & 8 & 1.8 & 5 & 2.4 & 14 & 5.8 & \\
\hline Total gastrectomy & 37 & 8.3 & 34 & 16.6 & 22 & 9.1 & \\
\hline Extended proximal gastrectomy & 8 & 1.8 & 2 & 1.0 & 5 & 2.1 & \\
\hline Open/close & 2 & 0.5 & 2 & 1.0 & 5 & 2.1 & \\
\hline PLO & 31 & 7.0 & 10 & 4.9 & 14 & 5.8 & \\
\hline
\end{tabular}

$P L O$, Pharyngo-laryngo-esophagectomy. ${ }^{*}$ Transhiatal esophagectomy rate $P=.027$.

Node-negative status was evident in $42.3 \%, 35.7 \%$, and $48.1 \%$ for periods 1 to 3 , respectively $(P=.446)$. A heavy nodal burden (N2/N3) was evident in $37 \%$ in period $1,37 \%$ in period 2 , and $36 \%$ in period $3(0.546)$. The $\mathrm{R} 0$ resection rate was significantly $(P<.01)$ improved in periods 2 and 3 compared with period 1 .

Multimodal cohort. A complete pathologic response (TRG1) was observed in $22 \%, 24 \%$, and $21 \%$ of patients in periods 1 to 3, respectively. A major response (TRG1 and TRG 2) was evident in $49 \%, 51 \%$, and $46 \%$ in periods 1 to 3 , respectively. Node negativity was $71 \%$ in period $1,57 \%$ in period 2 , and $40.4 \%$ in period $3(P<.001)$. The R0 resection rate was $81.8 \%$ in period 3 compared with $88.1 \%$ and $85.7 \%$ in periods 1 and 2 , respectively $(P=.427) . \mathrm{N} 2 / 3$ nodal burden represented $12 \%, 21 \%$, and $30 \%$ in periods 1 to 3 , respectively $(P=.01)$ (Table 4).

\section{Nodal Yield and Involvement}

For all groups, including surgery and multimodal cohorts, the median (range) number of nodes harvested was 11 (1-44) in period 1, $18(4-52)$ in period 2, and 22 $(8-62)$ in period $3(P<.05)$. The percentage of patients with a nodal yield greater than 15 was $50 \%, 78 \%$, and $90 \%$ in periods 1 to 3 , respectively $(P<.05)$.

\section{Operative Outcomes}

There were $4(1.7 \%)$ in-hospital postoperative deaths in period 3, a significant $(P<.001)$ improvement compared with $30(6.7 \%)$ in period 1 and $9(4.4 \%)$ in period 2

TABLE 3. Pathologic T and N stage: Patients treated with surgery only

\begin{tabular}{|c|c|c|c|c|}
\hline & 1990-1998 & 2003-2008 & 2004-2008 & \\
\hline Pathology & Surgery $n=320(\%)$ & Surgery $n=130 *(\%)$ & Surgery $n=131 *(\%)$ & $P$ value \\
\hline HGD/in situ & $5(1.1)$ & $2(1.5)$ & $5(3.8)$ & Early cancer rate $(\mathrm{Tis} / \mathrm{T} 1 / \mathrm{T} 2)<.00$ \\
\hline T0 & 0 & 0 & 0 & \\
\hline $\mathrm{T} 1$ & $19(5.5)$ & $11(8.5)$ & $40(30.5)$ & \\
\hline $\mathrm{T} 2$ & $28(8.0)$ & $28(21.5)$ & $22(16.8)$ & \\
\hline $\mathrm{T} 3$ & $254(77.0)$ & $74(56.9)$ & $59(45.0)$ & \\
\hline $\mathrm{T} 4$ & 14 & $15(11.5)$ & $5(3.8)$ & \\
\hline \multicolumn{5}{|l|}{ Nodal status } \\
\hline No & $132(42.3)$ & $46(35.7)$ & $63(48.1)$ & .108 \\
\hline N1 & $65(20.8)$ & $35(27.1)$ & $21(16.0)$ & .082 \\
\hline $\mathrm{N} 2$ & $65(20.8)$ & $30(23.3)$ & $24(18.3)$ & .519 \\
\hline N3 & $50(16.0)$ & $18(14.0)$ & $23(17.6)$ & .628 \\
\hline \multicolumn{5}{|l|}{ R0 resection } \\
\hline R0 & $232(73)$ & $98(75)$ & $106(81)$ & $P<.052004-2008$ vs others \\
\hline R1 & $87(27)$ & $32(25)$ & $25(19)$ & \\
\hline
\end{tabular}

$H G D$, High-grade dysplasia. *Excludes open and close laparotomy and endoscopic mucosal resection. 
TABLE 4. Pathologic T and N status and response to neoadjuvant treatment: Multimodal treatment group

\begin{tabular}{|c|c|c|c|c|}
\hline & 1990-1998 & 2003-2008 & 2004-2008 & \\
\hline Pathology & Multimodal $n=126,(\%)$ & Multimodal $\mathbf{n}=\mathbf{7 5},(\%)$ & Multimodal $\mathbf{n}=99,(\%)$ & $P$ value \\
\hline HGD/in situ & 0 & 0 & 0 & Early cancer rate $(\mathrm{Tis} / \mathrm{T} 1 / \mathrm{T} 2)<.001$ \\
\hline T0 & $29(23)$ & $14(18.7)$ & $24(24)$ & \\
\hline $\mathrm{T} 1$ & $26(20.6)$ & $16(19.3)$ & $11(11)$ & \\
\hline $\mathrm{T} 2$ & $21(16.7)$ & $15(20.0)$ & $17(17)$ & \\
\hline $\mathrm{T} 3$ & $47(37.3)$ & $29(38.7)$ & $46(46)$ & \\
\hline $\mathrm{T} 4$ & $3(2.4)$ & $1(0.01)$ & $1(1)$ & \\
\hline \multicolumn{5}{|l|}{ Nodal status } \\
\hline No & $89(71.2)$ & $43(57.3)$ & $40(40.4)$ & $<.001$ \\
\hline N1 & $21(16.8)$ & $15(20.0)$ & $29(29.3)$ & .062 \\
\hline $\mathrm{N} 2$ & $12(9.6)$ & $10(13.3)$ & $17(17.2)$ & .205 \\
\hline N3 & $3(2.4)$ & $5(6.7)$ & $13(13.1)$ & .01 \\
\hline \multicolumn{5}{|l|}{ Response } \\
\hline TRG 1 & $24(21.6)$ & $18(24.3)$ & $21(21)$ & .521 \\
\hline TRG 2 & $30(27.0)$ & $20(26.7)$ & $25(25)$ & \\
\hline TRG 3 & $23(20.7)$ & $17(22.7)$ & $26(26)$ & \\
\hline TRG 4 & $21(18.9)$ & $17(22.7)$ & $18(18)$ & \\
\hline TRG 5 & 13 (11.7) & $2(2.7)$ & $9(9)$ & \\
\hline Missing & 15 & 1 & 0 & \\
\hline \multicolumn{5}{|l|}{$\mathrm{R} 0$ resection } \\
\hline R0 & $111(88.1)$ & $64(85.7)$ & $81(81.8)$ & .427 \\
\hline $\mathrm{R} 1$ & 15 (11.9) & $11(14.7)$ & $18(18.2)$ & \\
\hline
\end{tabular}

$H G D$, High-grade dysplasia; $T R G$, tumor regression grade.

(Table 5). There was no significant difference across time periods in the incidence of pneumonia, anastomotic leaks, arrhythmias, myocardial infarction, or thromboembolic events, but the incidence of respiratory failure was significantly $(P<.05)$ decreased in period 3 compared with both other time periods.

\section{Survival}

In patients treated with curative intent, the median disease-specific survival in period 3 was significantly $(P<.05)$ increased at 33 months compared with 17 and 23 months for periods 1 and 2, respectively (Figure 1). At a median follow-up of 46 months and a minimum of 24 months, the actuarial 1-, 3-, and 5-year disease-specific survival for period 3 was $80 \%, 55 \%$, and $44 \%$, respectively. This compares with disease-specific survival of $65 \%, 36 \%$, and $28 \%$ for period 1 , and $75 \%, 43 \%$, and $35 \%$ for period 2 . The overall 5 -year survival for period 1 was $25 \%, 29 \%$ for period 2 , and $37 \%$ for period 3 .

In a univariate analysis of disease-specific survival (Table E3), age, sex, pT stage, pN stage, number of involved nodes, $\mathrm{R}$ status, venous invasion, and period of treatment were significantly $(P<.05)$ associated with survival. In multivariate analysis, age, nodal status, $\mathrm{T}$ stage, and venous invasion were significant, as well as the time period, with a hazard ratio of $0.415(0.315-0.547)$ for period 3, compared with $0.717(0.576-0.891)$ for period 2 and $2.41(1.829-3.176)$ for period 1 .

TABLE 5. Postoperative morbidity and mortality

\begin{tabular}{|c|c|c|c|c|c|c|c|}
\hline \multirow[b]{2}{*}{ Time period } & \multicolumn{2}{|c|}{ 1990-1998 } & \multicolumn{2}{|c|}{ 1999-2003 } & \multicolumn{2}{|c|}{ 2004-2008 } & \multirow[b]{2}{*}{$P$ value $\left(\chi^{2}\right)$} \\
\hline & $\mathbf{n}$ & $\%$ & $\mathbf{n}$ & $\%$ & $\mathbf{n}$ & $\%$ & \\
\hline 30-d mortality & 24 & 5.4 & 5 & 2.4 & 3 & 1.3 & \\
\hline 90-d mortality & 6 & & 3 & & 1 & & \\
\hline Total in-hospital mortality & 30 & 6.7 & 9 & 4.4 & 4 & 1.7 & $<.0001$ \\
\hline \multicolumn{8}{|l|}{ Respiratory } \\
\hline Pneumonia & 74 & 16.6 & 21 & 10.2 & 31 & 12.8 & \\
\hline Respiratory failure & 42 & 9.4 & 17 & 8.3 & 9 & 3.7 & $<.05$ \\
\hline \multicolumn{8}{|l|}{ Cardiovascular } \\
\hline Atrial fibrillation & 32 & 7.2 & 13 & 6.3 & 30 & 12.3 & NS \\
\hline Myocardial infarction & 3 & 0.006 & 2 & 0.01 & 4 & 1.6 & \\
\hline \multicolumn{8}{|l|}{ Anastomotic } \\
\hline Radiologic or clinical leak & 38 & 8.5 & 8 & 3.9 & 10 & 4.1 & NS \\
\hline Graft ischemia & 5 & 1.1 & 1 & 0.5 & 1 & 0.4 & \\
\hline
\end{tabular}




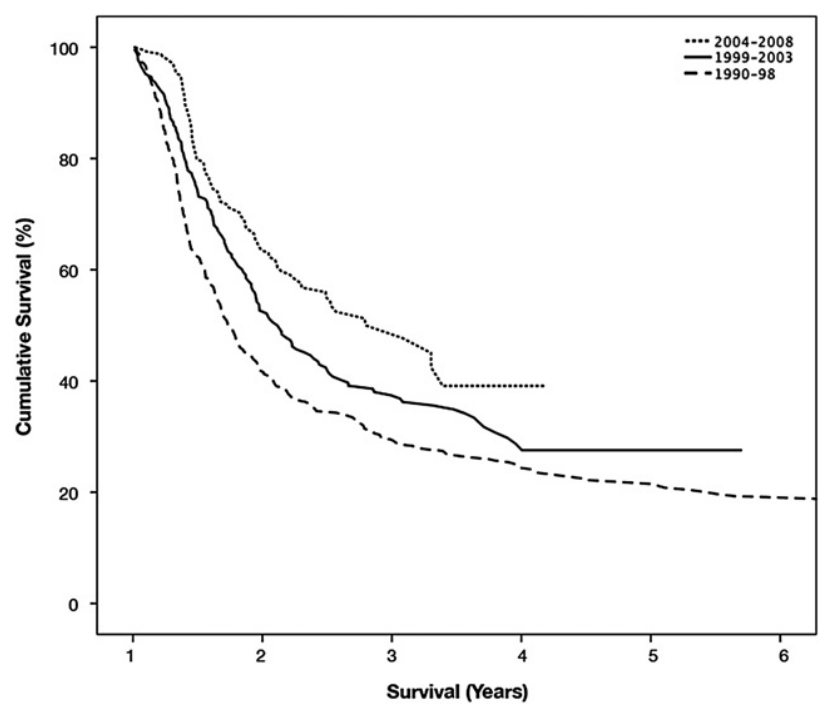

\begin{tabular}{|l|c|c|c|c|c|c|c|}
\hline & \multicolumn{2}{|c|}{$\mathbf{1 9 9 0 - 9 8}$} & \multicolumn{2}{|c|}{$\mathbf{1 9 9 9 - 2 0 0 3}$} & \multicolumn{2}{c|}{$\mathbf{2 0 0 4 - 0 8}$} & $\begin{array}{c}\text { p-value (log- } \\
\text { rank) }\end{array}$ \\
\hline & $\mathbf{N}$ & $\begin{array}{c}\mathbf{9 5} \% \\
\mathbf{C I}\end{array}$ & $\mathbf{n}$ & $\begin{array}{c}\mathbf{9 5} \% \\
\mathbf{C I}\end{array}$ & $\mathbf{n}$ & $\begin{array}{c}\mathbf{9 5} \% \\
\mathbf{C I}\end{array}$ & \\
\hline & 17.38 & $14.89-$ & 22.93 & $\begin{array}{c}18.29- \\
27.58\end{array}$ & 32.85 & $24.34-$ & 0.001 \\
\hline $\begin{array}{l}\text { Median survival } \\
\text { (months) }\end{array}$ & 19.87 & 22.15 & 0.001 \\
\hline
\end{tabular}

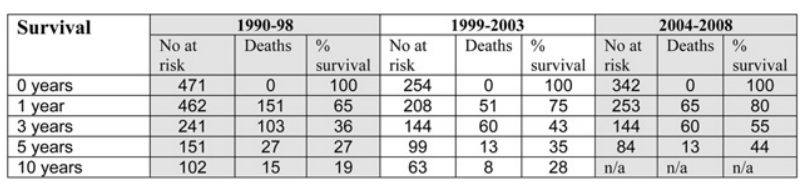

FIGURE 1. Disease-specific survival in patients treated with curative intent. $C I$, Confidence interval.

\section{DISCUSSION}

In the modern era, there is a consistent reported trend of markedly improved operative and oncologic outcomes from high-volume esophageal programs within academic medical centers. ${ }^{1-4}$ The current benchmark survival in patients treated with curative intent is $35 \%$ to $50 \%$, not $20 \%$ as commonly quoted, and postoperative deaths are rare, usually less than $4 \% .{ }^{17,18}$ The argument in favor of esophageal cancer being the exclusive domain of high-volume surgeons in high-volume centers is compelling, ${ }^{9}$ and there is evidence from Europe that organizational reform and centralization of esophageal cancer care may improve outcomes. ${ }^{19}$ Within high-volume centers, there is also evidence of improved outcomes over time, but factors that underpin such improvement are rarely studied or reported. ${ }^{18,20,21}$ Where significant improvements in oncologic and operative outcomes occur, does this reflect increased percentages of patients with early stage disease, improved staging, better treatment planning, better cancer surgery, greater use of multimodal approaches, advances in perioperative care, a combination of factors, or elements that cannot easily be measured? In this study of 1067 patients treated with curative intent, where all operations were performed by high-volume surgeons in a high-volume center, the most recent 5-year period is associated with markedly improved oncologic and operative outcomes. An increase in early cancers, the introduction of formal multidisciplinary processes, improved staging, an increased use of nonoperative therapies, and improvements in proxy measures of cancer surgery are all features of the current period that may underpin the attainment of improved outcomes.

A 5-year survival of $44 \%$ for the period $2004-2008$ is consistent with other series. ${ }^{2-4}$ A shift toward early-stage disease may be central to this finding, which now represents close to one fifth of patients presenting for curative therapy, compared with 1 in 20 a decade ago. Adenocarcinoma represented 38 of 42 early tumors in the recent time period; of these, $25(65 \%)$ were on Barrett's surveillance programs. In a report of 263 patients with adenocarcinoma treated over a 13 -year period by Portale and colleagues ${ }^{2}$ at the University of Southern California, the overall 5-year survival was $50 \%$, and pT1N0 represented approximately $50 \%$ of tumors in the final 2 years of the study. In this and our own series we do not know whether the increase in early tumors reflects a referral bias to a specialist center or a national trend consequent on improved awareness of Barrett's esophagus and early detection, and this demands further study. Similar trends internationally may exist for esophageal squamous cell cancer. From a multicenter study in Italy of predominantly squamous cell cancer, Ruol and colleagues $^{21}$ reported approximately $10 \%$ of patients with T0/T1 tumors in 1980-1987, compared with $15 \%$ in 1988-1995, and $28 \%$ in 1996-2004, with 5-year survival of $19 \%, 23 \%$, and $42 \%$, respectively.

Improved staging represents a key process measure that has significantly changed over the time periods, enabling better definition of patient cohorts who can be selected for treatment with curative intent. The decrease in patients treated with curative intent compared with the first time period suggests that staging and case selection have influenced decision-making. CT-PET would be expected to identify $5 \%$ to $17 \%$ of patients whose treatment plan may be altered compared with CT alone. ${ }^{22}$ The impact of EUS on the outcomes observed is unclear. EUS has the greatest value for staging of early cancer and has been available throughout each period but underused until 2007. It is now standard in combination with CT-PET for patients with localized disease, and in parallel with an increase in early cancer there has been increased use of EUS in combination with endoscopic mucosal resection for microstaging and curative therapy.

The approach to surgery and its extent did not significantly change over successive time periods, although quality indicators including nodal yield and negative margins were improved. Transthoracic esophagectomy with abdominal and thoracic lymphadenectomy is the dominant operation throughout. There is an increasing use of transhiatal 
esophagectomy for higher-risk patients and early disease, an approach that may be associated with lower respiratory risks compared with open thoracic surgery, and accounted for $5.4 \%$ of surgery in the recent period, compared with $1.7 \%$ in period 1 and $2.3 \%$ in period $2 .{ }^{18}$ The use of multimodal therapy significantly increased to $41 \%$ in period 3 compared with $27 \%$ in period 1 and $36 \%$ in period 2 . The same regimen spans the 3 time periods, based on the randomized trial conducted between 1990 and 1995, and combines cisplatin and fluorouracil and 40 to 44 Gy radiation therapy. ${ }^{6}$ Consistent treatment efficacy is shown by equivalent major (TRG 1 and 2) histomorphologic regression at the primary site at $48 \%, 51 \%$, and $45 \%$ for periods 1 to 3 , respectively. The patterns of care and pathology indicate that the indication for use has changed, consequent on improved staging and the lack of a randomized trial, suggesting that the use of multimodal therapy in the modern era in this center is predominantly in patients with predicted locally advanced disease or node-positive disease. This is shown by node-positivity rates in $29 \%$ of patients in period 1 compared with $40 \%$ in period 2 and $60 \%$ in period 3 despite a uniform regimen and identical effects at the primary site. There has also been an increased use of radical radiation therapy in combination with chemotherapy over time, because a number of recent series suggest that this approach may be equivalent to approaches involving surgery, particularly for squamous cell cancers. ${ }^{23}$

The operative mortality in the recent time period was less than $2 \%$, consistent with modern benchmarks from large single-center experience reported in the international literature, and markedly improved compared with collected series. ${ }^{1-4}$ Many factors may be important, including the improved case selection, selective use of transhiatal esophagectomy or nonoperative approaches for higher-risk patients, and development of relatively standardized care pathways in combination with anesthetists, critical care specialists, cardiologists, and specialist nurses. The lowest reported mortality rate from a large series is from Low and colleagues ${ }^{4}$ at the Virginia Mason Medical Center in Seattle, with 1 death in 340 patients $(0.3 \%)$ in a 17 -year series, results underpinned by standardized clinical pathways. Several key elements, including the use of thoracic epidurals, restricted intraoperative fluid, early mobilization, and enteral nutrition, are in place at this center. ${ }^{4}$ In this current series, the most significant change is reduced deaths and reduced respiratory failure, but other major morbidities remained constant, a finding consistent with other series. ${ }^{21}$

We acknowledge that changes in staging and decisionmaking make the time periods not exactly comparable. Moreover, elements of quality of care are difficult to measure. The most significant impact on improved outcomes may be from the surgeons, oncologists, and other specialist staff working closely together in defined multidisciplinary teams, a so-called virtuous circle of shared experience. ${ }^{24}$
This philosophy, focus, and drive are embedded widely in modern multidisciplinary care in cancer and complex surgery, and although these are nuanced and difficult to measure, they are likely to be a key factor where major quality improvements are observed. ${ }^{24}$ We suggest that the modern high-volume esophageal cancer program targets stage for stage cure rates consistent with the best reported benchmarks, and the avoidance of any postoperative death, and that this philosophy is the driving force in most highvolume centers dealing with esophageal or other complex cancers or surgery. ${ }^{25}$

\section{CONCLUSIONS}

This study addressed factors that may relate to a continuously evolving improvement in oncologic and operative outcomes in a high-volume center where adenocarcinoma is the dominant cancer and the lessons learned may apply to similar centers in the West. A marked increase in early cancers is likely to be a key factor, as well as improved clinical and pathologic staging, and the integration of the multidisciplinary team. The modern team has a shared commitment to standardized care pathways and a drive to avoid any postoperative death and achieve adequate nodal harvest and negative margins, and all these factors are likely to affect this encouraging trend.

The authors thank Dr Ewout Courrech Staal for reviewing the article.

\section{References}

1. Enzinger PC, Mayer RJ. Esophageal cancer. N Engl J Med. 2003;349:2241-52.

2. Portale G, Hagen JA, Peters JH, Chan LS, De Meester S, Gandamiharda TAK, et al. Modern 5-year survival of resectable esophageal adenocarcinoma: single institution experience with 263 patients. J Am Coll Surg. 2006;202:588-96.

3. Altorki N, Kent M, Ferrara C, Port J. Three-field lymph node dissection for squamous cell and adenocarcinoma of the esophagus. Ann Surg. 2002;236:177-83.

4. Low DE, Kunz S, Schembre D, Otero H, Malpass T, Hsi A, et al. Esophagectomy-it's not just about mortality anymore: standardized perioperative clinical pathways improve outcomes. J Gastrointest Surg. 2007;11:1395-402.

5. Courrech Staal EFW, Wouters MWJM, Boot H, Tollenaar RAEM, van Sandick JW. Quality of care indicators for oesophageal cancer surgery: a review. Eur J Surg Oncol. 2010;36:1035-43.

6. Reynolds JV, Muldoon C, Hollywood D, Ravi N, Rowley S, O'Byrne K, et al. Long-term outcomes following neoadjuvant chemoradiotherapy for esophageal cancer. Ann Surg. 2007;245:707-16.

7. Gebski V, Burmeister B, Smithers BM, Foo K, Zalcberg J, Simes J, et al. Survival benefits from neoadjuvant chemoradiotherapy or chemotherapy in oesophageal carcinoma: a meta-analysis. Lancet Oncol. 2007;8:226-34.

8. Birkmeyer JD, Siewers AE, Finlayson EV, Stukel TA, Lucas L, Batista I, et al. Hospital volume and surgical mortality in the United Stares. N Engl J Med. 2002;346:1128-37.

9. Siewert JR, Feith M, Werner M, Stein HJ. Adenocarcinoma of the esophagogastric junction: results of surgical therapy based on anatomical/topographical classification in 1002 consecutive patients. Ann Surg. 2000;232:353-61.

10. Macdonald JS, Smalley SR, Benedetti J, Hundahl SA, Estes NC, Stemmermann GN, et al. Chemoradiotherapy after surgery compared with surgery alone for adenocarcinoma of stomach or gastroesophageal junction. N Engl J Med. 2001;345:725-30.

11. Cunningham D, Allum W, Stenning SP, Thompson JN, Van de Velde CJH, Nicolson $\mathrm{M}$, et al. Perioperative chemotherapy versus surgery alone for resectable gastroesophageal cancer. N Engl J Med. 2006;355:11-20. 
12. Lerut T, Decker G, Coosemans W, de Leyn P, Decaluwe H, Nafteux P, et al. Quality indicators of surgery for adenocarcinoma of the esophagus and gastroesophageal junction. Recent Results Cancer Res. 2010;182:127-42.

13. Reynolds JV, Ravi N, Hollywood D, Kennedy J, Rowley S, Ryan A, et al. Neoadjuvant chemoradiation may increase the risk of respiratory complications and sepsis after transthoracic esophagectomy. J Thoracic Cardiovasc Surg. 2006; 132:549-55.

14. Ibrahim NB. Guidelines for handling oesophageal resection biopsies and resection specimens and their reporting. J Clin Pathol. 2000;53:89-94.

15. Edge SB, Byrd DR, Compton CC, Fritz AG, Greene FL, Trotti A, eds. AJCC cancer staging manual. 7th ed. New York, NY: Springer; 2010.

16. Mandard AM, Dalibard F, Mandard JC, Marnay J, Henry-Amar M, Petiot JF, et al. Pathologic assessment of tumor regression after preoperative chemoradiotherapy for esophageal carcinoma. Cancer. 1994;73:2680-6.

17. Lagarde SM, Vrouenraets BC, Stassen LP, can Lanschot JJ. Evidence-based surgical treatment of esophageal cancer; overview of high quality studies. Ann Thorac Surg. 2010;89:1319-26.

18. Orringer MB, Marshall B, Chang AC, Lee J, Pickens A, Lau CL. Two thousand transhiatal esophagectomies. Ann Surg. 2007;246:363-74.
19. Wouters MW, Karim-Kos HE, Le Cessie S, Wijnhoven BPL, Stassen LPS Steup WH, et al. Centralization of esophageal cancer surgery: does it improve clinical outcome? Ann Surg Oncol. 2009;16:1789-98.

20. Law S, Kwong DL, Kwok KF, Wong KH, Chu KM, Sham JS, et al. Improvement in treatment results and long term survival in patients with esophageal cancer: impact of chemoradiation and change in treatment strategy. Ann Surg. 2003; 238:339-47.

21. Ruol A, Castoro C, Portale G, Cavallin MS, Sileni VC, Cagol M, et al. Trends in management and prognosis for esophageal cancer surgery. Arch Surg. 2009;144 247-54.

22. Salahudeen HM, Balan A, Naik K, Mirsadree S, Scarsbrook AF. Impact of the in troduction of integrated PET-CT into the preoperative staging pathway of patients with potentially operable oesophageal carcinoma. Clin Radiol. 2008;63:765-73.

23. Bedenne L, Michel P, Bouche O, Milan C, Mariette C, Conroy T, et al. Chemoradiation followed by surgery compared with chemoradiation alone in squamous cancer of the esophagus: FFCD 9102. J Clin Oncol. 2007;25:1160-8.

24. Porter ME. Value-based health care delivery. Ann Surg. 2008;248:503-9.

25. American College of Surgeons. National Surgical Improvement Programme. Available at: http://www.acsnsqip.org/. Accessed April 8, 2011. 
TABLE E1. Demographics: All patients

\begin{tabular}{|c|c|c|c|c|c|c|c|}
\hline \multirow[b]{2}{*}{ Time period } & \multicolumn{2}{|c|}{ 1990-1998 } & \multicolumn{2}{|c|}{ 1999-2003 } & \multicolumn{2}{|c|}{ 2004-2008 } & \multirow[b]{2}{*}{$P$ value } \\
\hline & $\mathbf{n}=\mathbf{7 0 4}$ & $\%$ & $n=494$ & $\%$ & $\mathbf{n}=\mathbf{5 8 9}$ & $\%$ & \\
\hline Mean age (range) & $64 \mathrm{y}$ & $(28-86$ y) & $62 \mathrm{y}$ & $(26-83 \mathrm{y})$ & 65 & $(36-86$ y) & NS \\
\hline Male:female ratio & $2: 1$ & & $2: 1$ & & $2.2: 1$ & & NS \\
\hline Pathology & & & & & & & .003 \\
\hline Adenocarcinoma & 391 & 55.5 & 263 & 53.2 & 365 & 62 & \\
\hline Squamous cell & 293 & 41.6 & 221 & 44.9 & 196 & 33.3 & \\
\hline Other & 21 & 3 & 10 & 2 & 28 & 4.8 & \\
\hline Treatment intent: & & & & & & & $<.05$ \\
\hline Curative & 471 & 68 & 254 & 53 & 342 & 58 & \\
\hline Palliative & 233 & 32 & 240 & 47 & 247 & 42 & \\
\hline
\end{tabular}

TABLE E2. Staging and radiologic investigations

\begin{tabular}{|c|c|c|c|c|c|c|c|}
\hline & \multicolumn{2}{|c|}{ 1990-1998 } & \multicolumn{2}{|c|}{ 1999-2003 } & \multicolumn{2}{|c|}{ 2004-2008 } & \multirow[b]{2}{*}{$P$ value $\left(\chi^{2}\right)$} \\
\hline & $\mathbf{n}$ & $\%$ & $\mathbf{n}$ & $\%$ & $\mathbf{n}$ & $\%$ & \\
\hline Total patients staged & 704 & & 494 & & 589 & & \\
\hline CT scan & 165 & 23.4 & 467 & 94.5 & 579 & 98.3 & $<.001$ \\
\hline PET scan/CT-PET & 0 & 0 & 33 & 6.7 & 399 & 67.7 & $<.001$ \\
\hline EUS & 66 & 9.4 & 27 & 5.5 & 106 & 18.0 & $<.001$ \\
\hline Barium study & 348 & 49.4 & 130 & 26.3 & 69 & 11.7 & $<.001$ \\
\hline Total patients treated with curative intent & 471 & & 254 & & 342 & & \\
\hline CT scan & 145 & 30.8 & 254 & 100 & 342 & 100 & $<.001$ \\
\hline PET scan/CT-PET & 0 & 0 & 30 & 11.8 & 296 & 86.5 & $<.001$ \\
\hline EUS & 50 & 10.6 & 24 & 9.5 & 105 & 30.7 & $<.001$ \\
\hline Barium study & 257 & 54.6 & 64 & 25.1 & 36 & 10.5 & $<.001$ \\
\hline
\end{tabular}

CT, Computed tomography; EUS, endoscopic ultrasound; PET, positron emission tomography.

TABLE E3. Univariate and multivariate analysis of disease-specific survival of patients treated with curative intent

\begin{tabular}{|c|c|c|c|c|}
\hline \multirow[b]{2}{*}{ Factor } & \multicolumn{2}{|c|}{ Univariate analysis } & \multicolumn{2}{|c|}{ Multivariate analysis } \\
\hline & Hazard ratio $(95 \%$ CI $)$ & $P$ value & Hazard ratio $(95 \%$ CI $)$ & $P$ value \\
\hline Sex (male vs female) & $1.208(1.025-1.423)$ & .024 & $1.258(1.036-1.527)$ & .05 \\
\hline Age at diagnosis ( $>70$ vs $<70 \mathrm{y})$ & $1.017(1.009-1.024)$ & $<.001$ & $1.017(1.008-1.026)$ & $<.001$ \\
\hline Adenocarcinoma & $1.05(0.90-1.224)$ & .536 & Not in model & \\
\hline Node negative versus node positive & $0.445(0.379-0.552)$ & $<.001$ & $0.461(0.379-0.561)$ & $<.001$ \\
\hline $\mathrm{T} 1$ vs $\mathrm{T} 2 / 3$ & $0.395(0.324-0.483)$ & $<.001$ & $0.521(0.415-0.655)$ & $<.001$ \\
\hline $\mathrm{R} 0$ resection & $0.505(0.417-0.61)$ & $<.001$ & $0.706(0.572-0.87)$ & .001 \\
\hline Neoadjuvant treatment (yes) & $0.858(0.726-1.015)$ & .074 & Not in model & \\
\hline Did not undergo resectional surgery & $1.449(1.197-1.755)$ & $<.001$ & & $\mathrm{n} / \mathrm{a}$ \\
\hline Postoperative complications (yes) & $0.916(0.785-1.069)$ & .265 & Not in model & \\
\hline Junction tumor (yes) & $0.986(0.843-1.152)$ & .855 & Not in model & \\
\hline Lymphatic invasion & $2.46(2.053-2.947)$ & $<.001$ & $\chi^{2}=0.573$ & .484 \\
\hline Venous invasion & $1.49(1.195-1.857)$ & $<.001$ & $1.445(1.117-1.868)$ & .005 \\
\hline Perineural invasion & $1.47(1.177-1.836)$ & .001 & $\chi^{2}=0.49$ & .484 \\
\hline Time period of surgery: for trend & & $<.001$ & & $<.001$ \\
\hline $1990-1998$ vs others & $1.457(1.209-1.757)$ & $<.001$ & $2.41(1.829-3.176)$ & $<.001$ \\
\hline 1999-2003 vs others & $0.819(0.68-0.986)$ & .035 & $0.717(0.576-0.891)$ & .003 \\
\hline 2004-2008 vs others & $0.686(0.569-0.827)$ & $<.001$ & $0.415(0.315-0.547)$ & $<.001$ \\
\hline
\end{tabular}

CI, Confidence interval. 